\title{
Effect of LASER on Crestal Bone Loss Around Dental Implants Retaining Mandibular Overdenture
}

\author{
Original Hebatallah Tarek Mohamed ${ }^{a}$ and Marwa Kothayer ${ }^{a, b}$ \\ Article \\ ${ }^{a}$ Department of Oral and Maxillofacial Prosthodontics, Faculty of Dentistry, Ain \\ Shams University, Cairo, Egypt, ' Department of Substitutive Dental Sciences, \\ College of Dentistry, Taibah University, Al-Madinah Al-Munawarah, Saudi Arabia
}

\begin{abstract}
Objective: The aim of this study is to evaluate the effect of using both diode and erbium, chromium: yttrium-scandiumgallium-garnet (Er,Cr:YSGG) LASERs on crestal bone loss around dental implants retaining mandibular overdenture.

Materials and Methods: Cross over study on twelve patients selected from outpatient clinic faculty of dentistry, Ain Shams University to receive mandibular implant supported overdenture with and without laser application. The prepared osteotomy were treated with Er:Cr:YSGG $2780 \mathrm{~nm}$ LASER, and then implant was inserted, followed by applying diode $940 \mathrm{~nm}$ LASER for all the right sided implants and no laser application for the left sided implants. Cone beam CT was done to investigate crestal bone changes at zero, three, six and twelve months.

Results: The result of this study showed that there is a statistically significant higher crestal bone loss in group A implants (without laser application) in the first follow up period only (after three months), while after one year follow up there was non statistically significant difference between both groups.

Conclusion: Based on the results of this study it can be concluded that peri-implant crestal bone loss showed non statistically significant difference between the two groups after one year follow up period although it was significantly higher in group A implants (without laser application) in the first follow up period (from 0 - 3 months).
\end{abstract}

Key Words: Bone loss, Diode, Er:Cr:YSGG, Implants, Laser.

Received: 12 February 2021, Accepted: 23 June 2021.

Corresponding Author: Marwa Kothayer, Department of Oral and Maxillofacial Prosthodontics, Faculty of Dentistry, Ain Shams University, Cairo, Egypt, Mobile: +201224032120,+966565786953, E-mail: marwa_kothayer@dent.asu.edu.eg.

ISSN: 2090-097X, October 2020, Vol. 11, No. 4

\section{INTRODUCTION}

For several decades conventional complete denture was the treatment of choice for completely edentulous patients. Mandibular complete dentures represent problems in retention and stability. These problems rarely found in maxillary dentures due to the presence of large palatal vault and suction force. Tooth supported overdentures have problems; patient should achieve good oral hygiene to protect abutments against caries and periodontal disease and it is bulkier than conventional denture ${ }^{[1]}$.

Dental implants changed the concept of removable prosthodontics treatment options and expectations. Such treatment modalities need careful diagnosis, good treatment planning, long term evaluation to assure success and survival[ ${ }^{[2]}$.

Two Implant supported overdenture is considered the treatment modality of lower edentulous ridge as implant provides support, retention and patient satisfaction ${ }^{[3]}$.

LASERs have become widely used in both medicine and dentistry. In the mid of 1990's sudden evolvement in dental LASERs began, especially for diode laser systems with many functions and activities especially for performing soft tissue applications $\mathrm{s}^{[4]}$.
Several studies had suggested therapeutic effects of laser on the tissue repair process such as increased proliferation of epithelial cells and fibroblast, enhanced collagen synthesis, proliferation and maturation of the osteoblast, improves bone remodeling and repair; restores nerve function after injury; normalizes the hormonal function and reduce inflammation and edema; thus speeding the repair process ${ }^{[5]}$.

Several studies have suggested that Diode laser has beneficial effects on bone repair, it enhances the osteoblastic activity, collagen formation, and increases the rate of bone deposition when applied during the initial stages of bone repair, when cell proliferation is predominant, so nowadays studies are directed to evaluate the effect on dental implant osseointegration $^{[6]}$.

Regarding peri-implant bone healing after titanium implant placement, previously published studies have shown more evident bone maturation and increased bone-implant contact (BIC) in the irradiated groups when compared with the control groups ${ }^{[4,5,7]}$.

Erbium, chromium: yttrium-scandium-gallium-garnet (Er,Cr:YSGG) laser can be used to cut both bone and soft tissue as it is highly absorbed in water. On studying the 
effect of erbium LASER on bone when used to create bone defects, it was found to increase the osteoblastic activity, enhance osseointegration and results in shorter healing periods in comparison to bone defects caused by surgical $\operatorname{bur}^{[8]}$.

Cone beam CT is used during implant treatment planning to measure accurately the height and the width of bone and to avoid placing of implants in vital structures ${ }^{[9]}$.

So this study aimed to evaluate the effect of using both diode and Er,Cr:YSGG LASERs on the crestal bone loss around dental implants retaining mandibular overdenture.

\section{MATERIALS AND METHODS}

Cross over study on twelve completely edentulous male patients with age range between (55 - 65) years old from the outpatient clinic of Prosthodontic Department, Faculty of Dentistry, Ain Shams University.

Patients with adequate bone quantity and quality (type I or type II) of the residual ridges were selected. Patients with bad oral hygiene, alcoholic, smokers, patients with parafanctional habits, systemic diseases that might affect implant placement or previously received radiation therapy or chemotherapy were excluded.

In order to fulfill the predetermined criteria clinical, radiographic examinations as well as laboratory investigations were carried out for all patients.

In this study each patient received the two techniques of implant placement:

- Implants without laser application in the left side (Group A implants).

- Implants with diode and Er,Cr:YSGG laser application in the right side (Group B implants).

\section{Complete denture fabrication:}

Upper and lower special trays were fabricated on diagnostic casts. Secondary impressions were taken by border molding with green stick and zinc oxide and eugenol (S.S. White Zinc Oxide Impression Paste, S.S. White, England). Master casts were poured and occlusion blocks were fabricated.

Face bow records (Dentaus facebow.Type AFB. Jakobsdal. Svagen 14 - 16. S12653, Hagersten Sweden) were taken and mounting of maxillary casts were done. Then centric jaw relations were done for mounting of lower cast on a semi adjustable articulator (Dentaus articulator Type ARH Jakobsdal. Svagen 1416.S12653, Hagersten, Sweden).

Setting up of teeth according to the lingualized concept of occlusion was done. Try in were done in patients mouth for both upper and lower waxed up dentures. Then flasking and processing for both acrylic dentures were done. Cone beam $\mathrm{CT}$ and computer-aided surgical guides were made (Figure 1).

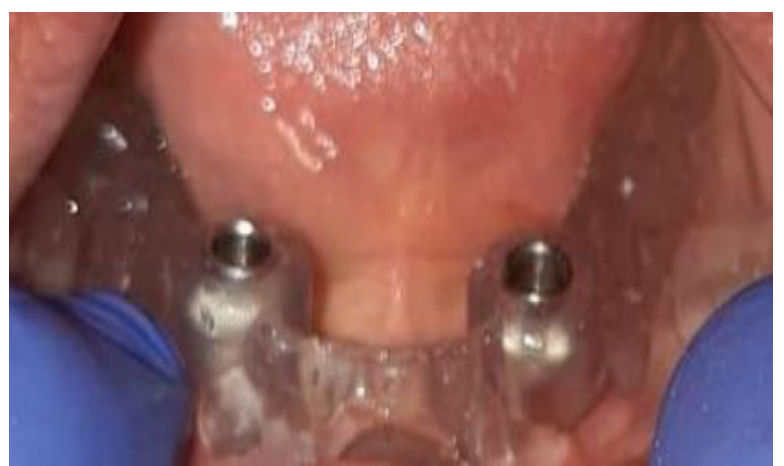

Figure 1: Surgical guide.

\section{Pre-surgical procedures:}

Detailed information about the treatment was given to all patients. The surgical and prosthetic steps, the risk, the benefits and the planned treatment alternatives were explained. All patients were motivated to the treatment and were informed to be a part in the study. Patients gave their acceptance by signing an informed consent.

The patient has been instructed to use a mouth wash (Chlorohexidine gluconate) every eight hours starting three days before surgery. The patient has been instructed to take a presurgical antibiotic (amoxicillin and clavulanate $1 \mathrm{gm})$ before surgery by one hour.

\section{Surgical procedures:}

Bilateral inferior alveolar nerve block has been administrated with infiltration anesthesia at the surgical field and the surgical guide was properly seated.

Cortical drill was used to mark location then osteotomy preparation was done starting with the pilot drill under proper cooling till final drill. Irrigation of osteotomy site with saline was done.

The prepared osteotomy for all the right sided implants were treated with Er:Cr:YSGG $2780 \mathrm{~nm}$ LASER, with the following configuration; power setting of 1.5 watt, frequency $50 \mathrm{~Hz}$, under irrigation $40 \%$ water and $20 \%$ air, using radial firing tip. First the RFT was inserted inside the osteotomy $1 \mathrm{~mm}$ away from its bottom, then the LASER was activated and the osteotomy was continuously radiated in a circular motion through from the bottom to the top to ensure the irradiation of the entire osteotomy.

Implants( Multisystem Dental Implant, Italy) were inserted with ratchet at torque not less than $40 \mathrm{Ncm}$, followed by applying diode $940 \mathrm{~nm}$ LASER set to the following parameters; pain therapy mode, with the power of 0.5 watt, for 30 seconds, continuous mode, and total energy 15 joule. 
Both the patient and the operator weared their protective goggles special for $940 \mathrm{~nm}$ diode LASER wavelength. Deep tissue hand piece was used to deliver the LASER beam to the buccal and the lingual surface of the mucosa at the implant sites at two points, coronal point and apical one. Each patient received a total of 5 sessions, one session on the day of implant placement followed by two
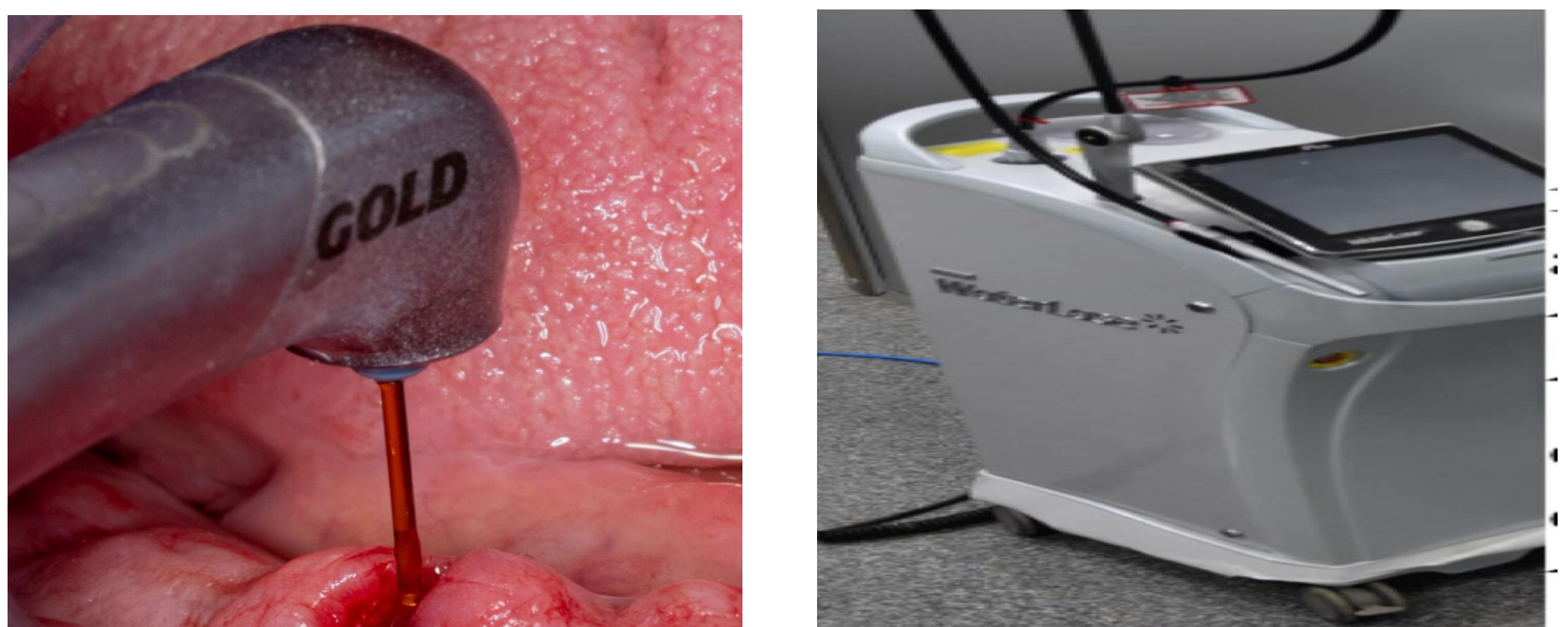

sessions per week for two weeks. (BIOLASE company, Europe GmbH, Paintweg 10, 92685 Floss, Germany). (Figures 2 and 3).

Ball abutments were joined to implant and then irrigation with saline was done. At the same day of surgery denture was completely relieved over abutments and was inserted.

Figure 2: RFT inserted into the osteotomy.

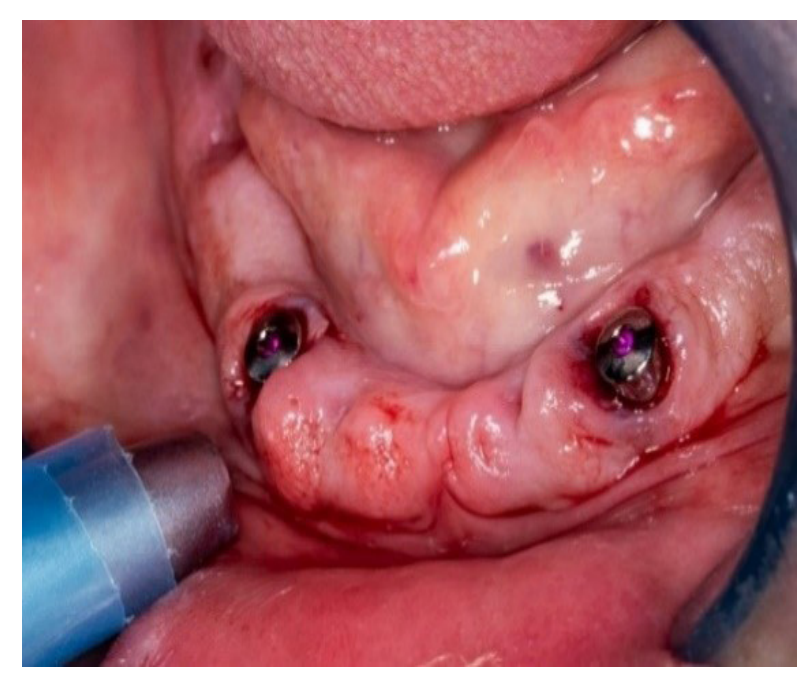

Figure 3: Diode LASER beam applied using deep tissue hand piece. 
One week after surgery patient was recalled: The fitting surface of denture was cleaned and dried to receive silicone soft liner. (MucoprenR Soft, Kettenbach, Germany.) Denture was fitted intra-orally and left to set for 10 minutes while patient in centric occlusion.

After six weeks patients were recalled for replacement of soft liner with ball and socket by direct pick up technique using auto-polymerized acrylic resin. Block out shims was inserted around ball abutment. Metal caps were inserted over it. Direct pick up with auto-polymerizing acrylic resin was done.(Duralay Self Cure Acrylic PINK, Reliance,Germany.) Excess material was trimmed.
Insertion of denture was checked out.Occlusion was checked. Delivery of denture with oral hygiene structures were given and regular recall visits were scheduled. (Figure 4).

Cone beam tomography was done for the mandible of all patients on the day of implant insertion, three, six and twelve months after implant loading. (Figure 5).

A software ruler was used to measure the crestal bone height in contact with the implants buccally and lingually in the sagittal view. Crestal bone height measured mesially and distally at the coronal view.

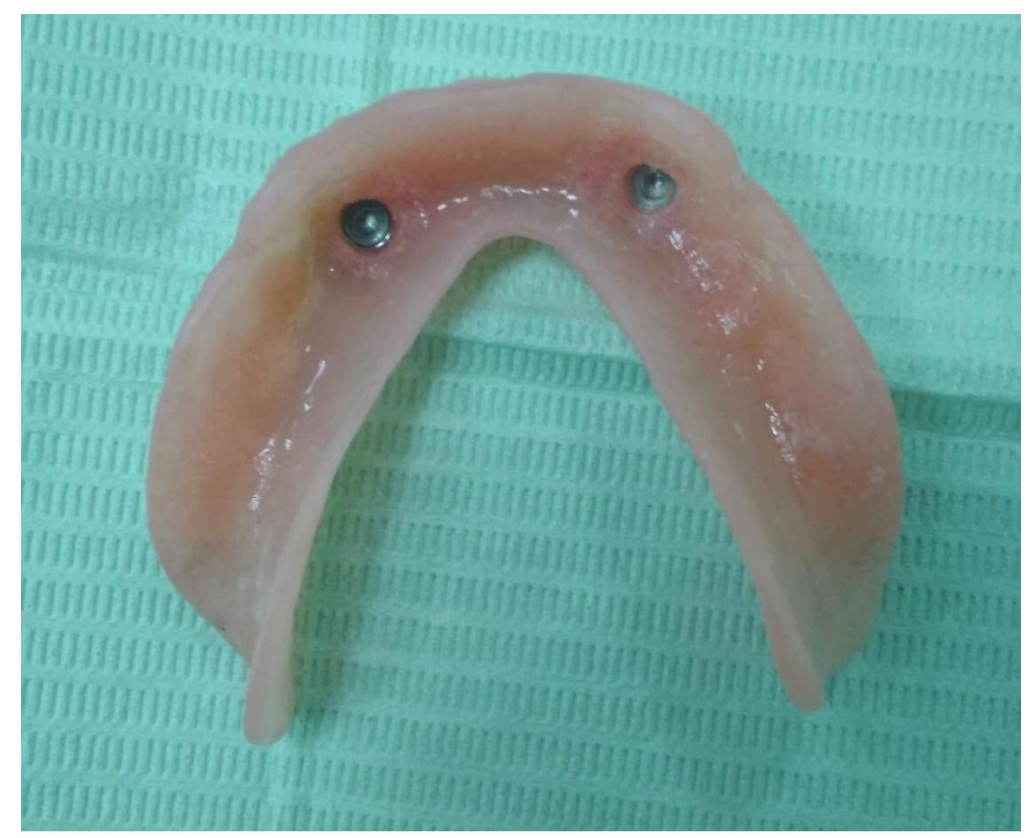

Figure 4: Denture with metal housing.
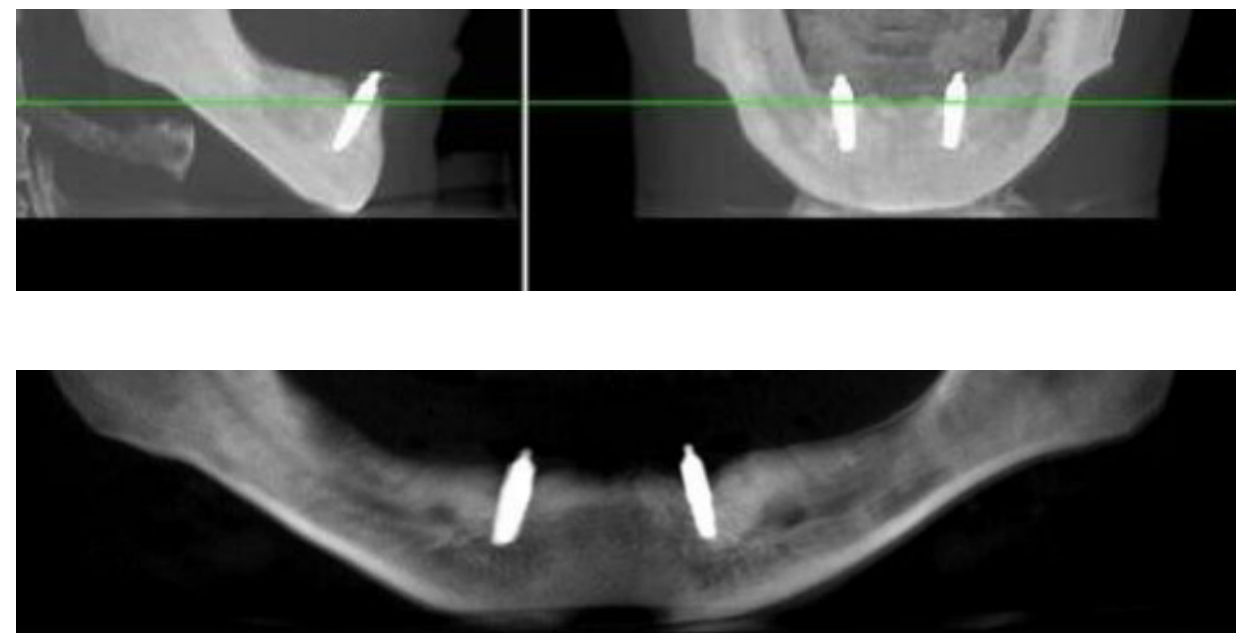

Figure 5: Cone beam CT. 


\section{RESULTS}

Values were presented as mean, standard deviation and $p$ value. The results in (Table 1).

From 0 to three months a higher mean value was recorded in the group A in the labial, lingual, mesial and distal surfaces compared to group B. Unpaired test revealed that the difference between both groups was statistically significant, except in the mesial surface which showed a non significant difference.

From three to six months, a higher mean value was recorded in the group B in the labial, lingual and distal surfaces compared to group A. However, in the mesial side a higher mean value was recorded in group A. unpaired $t$ test revealed that the difference between both groups was not statistically significant.

From six to twelve months, a higher mean value was recorded in the group $\mathrm{A}$ in the labial, lingual and distal surfaces. However, in the mesial side a higher mean value was recorded in group B. Paired t test revealed that the difference between both groups was not statistically significant.

Throughout the study period (0 - 12 months), a higher mean value was recorded in the group A in the labial,lingual, mesial and distal surfaces compared to group B. Unpaired $t$ test revealed that the difference between both groups was not statistically significant.

Table 1: Mean difference ( $\mathrm{mm}$ ), standard deviation and $\mathrm{p}$ value of peri-implant bone height loss measured at buccal, lingual, mesial, and distal surfaces for group A and B during the follow-up period:

\begin{tabular}{|c|c|c|c|c|c|c|}
\hline \multirow[b]{2}{*}{ Period } & \multirow[b]{2}{*}{ Surface } & \multicolumn{2}{|c|}{ Group A } & \multicolumn{2}{|c|}{ Group B } & \multirow{2}{*}{$\begin{array}{c}P \\
\text { value }\end{array}$} \\
\hline & & $\begin{array}{c}\text { Mean } \\
\text { Diff }\end{array}$ & $\pm \mathrm{SD}$ & $\begin{array}{c}\text { Mean } \\
\text { Diff }\end{array}$ & $\pm \mathrm{SD}$ & \\
\hline \multirow{4}{*}{$\begin{array}{c}0-3 \\
\text { Months }\end{array}$} & labial & 0.31 & 0.09 & 0.19 & 0.06 & $0.02 *$ \\
\hline & Lingual & 0.32 & 0.09 & 0.20 & 0.05 & $0.01 *$ \\
\hline & Mesial & 0.25 & 0.06 & 0.23 & 0.09 & 0.6 \\
\hline & Distal & 0.35 & 0.12 & 0.22 & 0.05 & $0.03 *$ \\
\hline \multirow{4}{*}{$\begin{array}{c}3-6 \\
\text { Months }\end{array}$} & labial & 0.25 & 0.07 & 0.26 & 0.05 & 0.7 \\
\hline & Lingual & 0.25 & 0.06 & 0.28 & 0.06 & 0.4 \\
\hline & Mesial & 0.31 & 0.07 & 0.29 & 0.09 & 0.3 \\
\hline & Distal & 0.27 & 0.07 & 0.33 & 0.12 & 0.3 \\
\hline \multirow{4}{*}{$\begin{array}{l}6-12 \\
\text { Months }\end{array}$} & labial & 0.17 & 0.04 & 0.16 & 0.08 & 0.7 \\
\hline & Lingual & 0.27 & 0.08 & 0.24 & 0.08 & 1 \\
\hline & Mesial & 0.17 & 0.05 & 0.22 & 0.09 & 0.1 \\
\hline & Distal & 0.23 & 0.06 & 0.20 & 0.07 & 0.4 \\
\hline \multirow{4}{*}{$\begin{array}{l}0-12 \\
\text { Months }\end{array}$} & labial & 0.72 & 0.15 & 0.61 & 0.06 & 0.1 \\
\hline & Lingual & 0.85 & 0.16 & 0.72 & 0.06 & 0.09 \\
\hline & Mesial & 0.75 & 0.08 & 0.74 & 0.09 & 1 \\
\hline & Distal & 0.85 & 0.19 & $\begin{array}{c}0.7 \\
5\end{array}$ & 0.08 & 0.2 \\
\hline
\end{tabular}

SD.: Standard Deviation. *Statistically significant $P \leq 0.05$.

\section{DISCUSSION}

The mandible was used in this study for implant placement, As the amount of bone resorption is greater in the mandible than maxilla, the mandibular denture usually shows greater clinical problem for patient and prosthodontist. Patients frequently complain of ill-fitting denture also the retention and stability of lower dentures are limited ${ }^{[10]}$.

Para-functional habits such as clenching and bruxism were known to perform excess load on implants so patients with these habits were excluded ${ }^{[1]}$.

One of the main causes of osseointegration failure is lack of proper oral hygiene. Therefore, Patients with poor oral hygiene were excluded to avoid the risk of periimplant mucositis and peri-implantitis ${ }^{[12]}$.

Age is an important factor that affect the behavior of residual ridge, muscles, oral mucosa and the temporomandibular joint. So selected patients had an age range between 55 and 65 years. Only male patients were selected to participate in this study to avoid the effect of sex related hormonal changes which cause mucosal changes and osteoporosis ${ }^{[13,14]}$.

Head and neck radiation therapy was another exclusion criterion, as the failure rates of implants were reported to be higher when they were placed in irradiated bone due to the reduced resistance to infection, delayed wound healing and the potential for osteoradionecrosis after radiation treatment ${ }^{[15]}$.

In order to standardize all factors that might interfere with the results, in this study the two techniques were done in the same patient. The right implants were placed with laser treatment and the left implants without laser treatment.

A surgical guide was designed and fabricated by using the implant planning software to place the implant in the preplanned position. Placement of dental implant with the aid of computer-aided surgical guide had several benefits. The most important benefit is the use of flapless technique which characterized by less pain, less trauma and less surgical time. It also allows the implants immediate loading ${ }^{[16]}$.

After sequential drilling was done, Er:Cr:YSGG LASER was used to condition the osteotomy because of its bactericidal effect to disinfect the osteotomy and reduce the risk of postoperative infection, also to promote the differentiation of the osteoblasts and allow for faster bone formation $^{[17]}$.

Radial firing tip (RFT) was used to deliver Er:Cr:YSGG LASER beam because of its conical outline allow better 
distribution of the LASER beam and even distribution of the light energy ${ }^{[18]}$.

After the insertion of the implants, low level diode LASER with $940 \mathrm{~nm}$ wavelength was used because of its biostimulatory effect which cause immediate relief of pain, as result of blood vessels vasodilatation and decreased level of inflammatory mediators ${ }^{[19]}$.

Diode LASER promote the wound healing process by increasing the release of the growth factors, increase production of ATP, enhance the proliferation of fibroblast, osteoblast, endothelial cells, lymphocytes and macrophage, and promote the collagen synthesis ${ }^{[20]}$.

In this study exposure time and intensity was in acceptance with other review that showed that exposure time range between $30: 120$ seconds had beneficial effects. Furthermore, irradiation was done in the first two weeks as it was reported that it had more pronounced effect in early stage of bone healing ${ }^{[21,22]}$.

Irrigation during drilling was done to reduce the harmful effect of drilling at osteotomy site by dissipation of heat ${ }^{[23]}$.

At the same day of surgery Denture was delivered and relieved over the abutments to avoid load on implants.

There is an idea based on practical information suggests that gradual loading to implants will allow maturation and denser growth of bone to occur. So progressive loading was used in this study to allow development of denser and stronger bone which withstand greater forces ${ }^{[24]}$.

Alveolar bone height around implants was measured in relation to the implant apex. A horizontal tangent line was drawn to the apex of implant and then three successive vertical measures was taken for alveolar bone height for each side and the mean length of three measures for each side was taken for reliability of the measured height ${ }^{[25]}$.

Dental implants were successfully osseointegrated due to positive response of surrounding host tissues. In addition to selecting implants with suitable design and surface texture which enhances biointegration and bone regeneration process ${ }^{[26]}$.

Crestal bone loss has been documented as one of the most important factors that affects the long term prognosis of dental implants. Crestal bone loss in four aspects (labial, lingual, mesial and distal) surrounding dental implant can be due to surgical trauma, bone remodeling process and functional stresses ${ }^{[27]}$.

Crestal bone loss is within the normal range during the first year of implant placement and loading. The criteria of success of dental implant include average bone loss of less than $1.5 \mathrm{~mm}$ during the first year after loading with the prostheses $^{[28]}$.

The result of this study showed that there is a statistically significant difference in bone loss between both groups, in the first follow up period only (after three months), as revealed in other study, the effect of diode laser on the marginal bone level radiographically at 3 and 6 months was assessed and it was found that. a statistically significant difference in the marginal bone level was in favor to the laser group ${ }^{[29]}$.

It was concluded that the application of low level laser irradiation around dental implants reduced the crestal bone resorption during the early phases of bone regeneration. This is might be due to enhance osteoblast cell attachment and activity, enhance collagen formation, increase calcium phosphate production, and ultimately increase bone matrix production and mineralization. It promotes bone regeneration and speed up dental implant integration in the early healing phases following their placement ${ }^{[30,31]}$.

Reduction of inflammatory cells and accelerated bone regeneration with the proliferation of fibroblasts and osteoblasts were observed on the Histological level after the use of diode laser ${ }^{[32]}$.

Diode LASER causes increase in the production of ATP, release of growth factors and other cytokines, proliferation of macrophages, lymphocytes, fibroblasts, and collagen synthesis. It also enhances the microcirculation reducing pain and edema ${ }^{[20]}$.

When comparing bone loss between the two groups, the result of this study showed that after one year follow up there was no statistically significant difference between both groups and this result is in acceptance with another study that evaluated the effect of laser treatment on implants inserted in the posterior maxilla and their results showed that although laser increased bone formation but no significant effect detected ${ }^{[33]}$. This is due to the effect of both Er,Cr:YSGG and diode LASER on the bone remodeling process.

Er,Cr:YSGG LASER has An ability to kill the bacteria by their photo-thermal effect, and inactivate their toxic substances causing disinfection of the surgical field, reducing the risk of infection and promoting the postoperative healing process, it also has an osteoinduction effect promoting the formation of new bone cells and faster lay down of new bone layers ${ }^{[34,35]}$.

This was proved by a study which showed that bony defects resulting from the use of Er,Cr:YSGG LASER showed more new bone formation when compared with that produced by surgical bur ${ }^{[8]}$.

\section{CONCLUSION}

Based on the results of this study it can be concluded that peri-implant crestal bone loss showed non statistically significant difference between the two groups after one year follow up period although it was significantly higher in group A implants (without laser application) in the first follow up period (from 0 - 3 months). 


\section{CONFLICT OF INTEREST}

The authors declare no conflict of interest.

\section{REFERENCES}

1. Samra RK, Bhide SV, Goyal C et al. Tooth supported overdenture: A concept overshadowed but not yet forgotten. J Oral Res Rev.2017; 7: 16 - 29.

2. Gowd MS, Shankar T, Ranjan R, Singh A. Prosthetic consideration in implant-supported prosthesis: a review of literature. J Int Soc Prev Community Dent. 2017; 7: 1 - 7.

3. Sharka R,Abed H. Hector M: Oral healthrelated quality of life and satisfaction of edentulous patients using conventional complete dentures and implant-retained overdentures: an umbrella systematic review. Gerodontol, 2019; 36; 195 - 204.

4. Niemz MH. Medical Applications of Lasers. In: Laser-tissue interactions: fundamentals and applications. 2007; $151-248$.

5. Gomes F V., Mayer L, Massotti FP, Baraldi CE, Ponzoni D, Webber JBB, et al. Low-level laser therapy improves peri-implant bone formation: Resonance frequency, electron microscopy, and stereology findings in a rabbit model. Int $\mathbf{J}$ Oral Maxillofac Surg. 2015; 44: 245 - 51.

6. Campanha BP, Gallina C, Geremia T, Loro RCD, Valiati R, Hübler R, et al. Low-Level Laser Therapy for Implants Without Initial Stability. Photomed Laser Surg. 2010; 28: 365 - 9.

7. Jakse N, Payer M, Tangl S, Berghold A, Kirmeier R, Lorenzoni M. Influence of lowlevel laser treatment on bone regeneration and osseointegration of dental implants following sinus augmentation: An experimental study on sheep. Clin Oral Implants Res. 2007; 18: $517-24$.

8. Perussi LR, Pavone C, De Oliveira GJPL, Cerri PS, Marcantonio RAC. Effects of the Er,Cr:YSGG laser on bone and soft tissue in a rat model. Lasers Med Sci. 2012; 27: 95 - 102.

9. Raju N, Zhang W, Jadhav A, Ioannou A, Eswaran S, Weltman R.Cone beam computed tomography analysis of the prevalence, length, and passage of the anterior loop of the mandibular canal. J Oral Implant. 2019; 45: $463-468$.
10. Nkenke, E,Neukam FW. Autogenous bone harvesting and grafting in advanced jaw resorption: morbidity, resorption and implant survival. Eur J Oral Implantol. 2014; 2; 203 - 217.

11. Reddy SV, Kumar MP, Sravanthi D, Mohsin AHB, Anuhya V. Bruxism. A Literature Review. J Int Oral Health. 2014; 6: $105-109$.

12. Fu J.-H., Wang HL. Breaking the wave of periimplantitis. Periodontol.2020; 84, $145-160$.

13. Giro G, Chambrone L, Goldstein A, Rodrigues JA, Zenóbio E, Feres et al. Impact of osteoporosisindental implants: Asystematicreview. World J Orthop. 2015; 6: 311 - 315.

14. Gallagher JC, Tella SH. Prevention and treatment of postmenopausal osteoporosis. J S t e r o i d BiochemMol Biol. 2014; 142: 155 - 170.

15. Shugaa-Addin B, Al-Shamiri H-M, Al-Maweri S, TarakjiB. The effect of radiotherapy on survival of dental implants in head and neck cancer patients. J ClinExp Dent. 2016; 8: 194 - 200.

16. Oh KC, Jeon C, Park JM, Shim JS. Digital workflow to provide an immediate interim restoration after single-implant placement by using a surgical guide and a matrix- positioning device. J. Prosthet. Dent. 2019; 121; $17-21$.

17. Arnabat AJ, España. laser applications in implantology. universal puplisher, USA, 2018.

18. Schoop U, Barylyak A, Goharkhay K, Beer F, Wernisch J, Georgopoulos A, et al. The impact of an erbium, chromium:yttrium-scandium-galliumgarnet laser with radial-firing tips on endodontic treatment. Lasers Med Sci. 2009; 24: 59 - 65.

19. Convissar R. Principles and Practice of Laser Dentistry. Elsevier; 2015.

20. Parker S. Low-level laser use in dentistry. Br Dent J. 2007; 202: $131-138$.

21. Prados-Frutos JC, Rodríguez-Molinero J, PradosPrivado M, Torres JH, Rojo R: Lack of clinical evidence on low-level laser therapy (LLLT) on dental titanium implant: a systematic review. Lasers Med Sci. 2016; 31: 383 - 392.

22. Pinheiro A, Martinez Gerbi ME, de Assis Limeira $\mathrm{F}$, et al. Bone repair following bone grafting hydroxyapatite guided bone regeneration 
and infra-red laser photobiomodulation: a histological study in a rodent model. Lasers Med Sci. 2009; 24: 234 - 240.

23. D. Flanagan, "Osteotomy irrigation: is it necessary?”. Implant Dent. 2010; 19: 241 - 249.

24. Misch CE: Progressive bone loading. St Louis, MO. Elsevier Mosby, 2005. 26: 511.

25. Abd El-wahab KA, Adel Aziz E, Abd El-Monaem NM: The effect of two loading protocols on the supporting structures of mini implants supporting mandibular overdenture. CPOI,. 2012; 3: 3 - 11.

26. Chenicheri S, Komeri R. Integration of dental implants: Molecular interplay and microbial transit at tissue-material interface. Biointegration of medical implant materials. Cambridge, UK: Woodhead Publishing; 2020; 221 - 243.

27. Cochran DL, Nummikoski PV, Schoolfield JD et al: A prospective multicenter 5-year radiographic evaluation of crestal bone levels over time in 596 dental implants placed in192 patients. j periodont, 2009; 80: 720 - 725.

28. Wiskott HW and Belser CL: Lack of integration of smooth titanium surfaces: A working hypothesis based on strains generated in the surrounding bone. Clin Oral Implants Res, 1999; 10: 429 - 441.

29. El-Kholey KE and El-Shenaway H. "Role of Diode Laser in Preservation of The Marginal
Bone Around Early Loaded Endosseous Implant". Life Science J. 2012; 9, 940 - 943.

30. Zein R, Selting W, Benedicenti S. Effect of lowlevel laser therapy on bone regeneration during osseointegration and bone graft. Photomed Laser Surg. 2017; 35: 649 - 658.

31. Gulati P, Kumar M. Effect of low level laser therapy on crestal bone levels around dental implants-A pilot study. Clin Implant Dent Relat Res. 2020; 22: 739 - 746.

32. Park JJ, Kang KL. Effect of 980-nm GaAlAs diode laser irradiation on healing of extraction sockets in streptozotocin-induced diabetic rats: a pilot study. Lasers Med Sci. 2012; 27: 223 - 230.

33. Mandić B. "Influence of postoperative low-level laser therapy on osseointegration of selftapping implants into posterior maxilla. A 6-week split-mouth clinical study". Vojnosanitetski Pregled. 2015; 72, 233 - 240.

34. Aoki AMK, Schwarz F, Sculean A, Takasaki AA, Romanos GE, Taniguchi Y et al, Sasaki KM, Zeredo JL, Koshy G, Coluzzi DJ, White JM, Abiko Y, Ishikawa I, Izumi Y. Periodontal and peri-implant wound healing following laser therapy. Periodontol 2000. 2015; 68: 217 - 269.

35. Kusek ER. The Use of Laser Technology (Er;Cr:YSGG) and Stereolithography to Aid in the Placement of a Subperiosteal Implant: Case Study. J Oral Implantol. 2009; 36: 5 - 11. 